\title{
Inverse effect of strain rate on mechanical behavior and phase transformation of superaustenitic stainless steel
}

\author{
Chia-Chang Wu, ${ }^{\text {a }}$ Shing-Hoa Wang,,${ }^{\mathrm{a}, *}$ Chih-Yuan Chen, ${ }^{\mathrm{b}}$ Jer-Ren Yang, ${ }^{\mathrm{b}}$ \\ Po-Kay Chiuc and Jason Fang ${ }^{\mathrm{d}}$ \\ ${ }^{a}$ Department of Mechanical Engineering, No 2, Pei-Ning Road, National Taiwan Ocean University, Keelung 20224, Taiwan \\ ${ }^{\mathrm{b}}$ Institute of Materials Science and Engineering, National Taiwan University, Taipei 10617, Taiwan \\ ${ }^{\mathrm{c}}$ Instrument Technology Research Center, National Applied Research Laboratories, Hsinchu 30076, Taiwan \\ ${ }^{\mathrm{d}}$ Outo Kumpu Asia Pacific, Hsin Chuang 24250, Taiwan
}

Received 6 May 2006; revised 20 July 2006; accepted 21 August 2006

Available online 6 February 2007

\begin{abstract}
In general, the strength of materials rises with an increase in the strain rate, while the ductility decreases. However, the ductility of superaustenitic stainless steel increases significantly with an increase in the strain rate. This is associated with strain-induced $\varepsilon$ martensite transformation. The higher the strain rates applied, the more strain-induced, intersected $\varepsilon$ martensite is formed. (c) 2006 Acta Materialia Inc. Published by Elsevier Ltd. All rights reserved.
\end{abstract}

Keywords: Superaustenitic stainless steel; Strain-induced martensite; Strain rate, Elongation

The superiority of superaustenitic stainless steel, 254 SMO (S31254), lies in its high strength, good weldability and great resistance to stress corrosion and pitting because of its higher content of alloying chromium and molybdenum compared to general stainless steel. It has been reported that laser cladding of S31254 on the surface of carbon steel can improve the corrosion resistance of the steel [1]. It also has been shown that 254 SMO steel has the ability to resist localized corrosion attacks in many acid solutions. In addition to its remarkable chemical properties, the fatigue properties of low cycle fatigue of superaustenitic 254 SMO steel are superior to those of duplex stainless steels [2]. Furthermore, the true stress-strain curves for monophasic superaustenitic $254 \mathrm{SMO}$ steel exhibit a higher true stress at a dynamic strain rate of $5 \times 10^{3} \mathrm{~s}^{-1}$ than at $8.5 \times 10^{2} \mathrm{~s}^{-1}$ [3]. The diffuse Lüders band appears at the surface of soft superaustenitic 254 SMO steel after impact at the higher strain rate of $5 \times 10^{3} \mathrm{~s}^{-1}[3]$.

Previous work has investigated the transformationinduced ductility behavior observed in stainless steels. The austenitic phase of most AISI 300 series alloys is metastable, and the martensite transformation $\gamma \rightarrow \alpha^{\prime}$

\footnotetext{
* Corresponding author. Tel.: +886 2 24622192x3221; fax: +8862 24620836; e-mail: shwang@mail.ntou.edu.tw
}

can occur during cooling and/or plastic straining. The low carbon and nitrogen content of $316 \mathrm{LN}$ stainless steel subjected $[5,6]$ to monotonic stress and cyclic stresses at low temperature reveals much higher straininduced $\alpha^{\prime}$ martensite than at room temperature. Strain-induced $\varepsilon$ martensite can result in a higher elongation under monotonic loading at $77 \mathrm{~K}$ [5]. Depending on the chemical composition, as well as the deformation rate and/or temperature for austenitic stainless steel, several transformation mechanisms could take place, such as $\gamma \rightarrow \varepsilon, \varepsilon \rightarrow \alpha^{\prime}, \gamma \rightarrow \alpha^{\prime}, \gamma \rightarrow \varepsilon \rightarrow \alpha^{\prime}$ [7]. The volume per cent of the phase has a great effect on the mechanical properties (strength, strain) and other behavior. By carefully controlling the volume fraction of martensites, a large strain can be obtained even at a low deformation temperature. This is called the transformation-induced plasticity (TRIP) effect [4]. TRIP steels are high in alloy content and are known to combine high strength with high ductility. The high ductility of this type of steel results from the transformation of metastable retained austenite to martensite under plastic strain. This transformation is accompanied by a volume expansion and results in a localized increase of the strain-hardening coefficient during deformation [8]. The strain-hardening delays the onset of necking and leads to more uniform and total elongation. However, if the transformation is too rapid, the material quickly 
becomes saturated with martensite and the transformation will be complete at relatively small plastic strain. Without any transformation plasticity to stabilize the material at high stresses, the ductility will decrease [7-9].

Some researchers consider that austenite can transform into brittle martensite under certain stress cycles, thus accelerating crack propagation and decreasing crack resistance. Others claim that strain-induced martensite transformation can increase crack resistance [10]. Recently it has been reported that the plastic deformation-induced martensite transformation can occur in the duplex stainless steel SAF 2205 as the result of low cycle fatigue $[10,11]$. At a strain amplitude of $0.9 \%$ with a strain ratio of -0.2 , the metastable austenitic phase transforms to the $\varepsilon$ martensite, intersected mutually. Furthermore, at a relatively higher strain ratio of -1 , the austenitic phase transforms into thin, lath-like $\alpha^{\prime}$ martensite sheaths $[10,11]$. The purpose of this paper is to investigate the effect of strain rate on the mechanical properties and microstructure variation of the superaustenitic stainless steel 254 SMO.

The chemical composition of the superaustenitic 254 SMO steel was analyzed by glow discharge spectrometry (LECO GDS-750 QDP), and the data are listed in Table 1. The tensile tests were performed at four strain rates: $1 \times 10^{-1}, 1 \times 10^{-2}, 1 \times 10^{-3}$ and $1 \times 10^{-4} \mathrm{~s}^{-1}$. The tensile specimen consisted of a reduction area $32 \times 4 \times 5 \mathrm{~mm}$ thick. Optical metallography was performed by electrolytic etching with a solution composed of $5 \mathrm{~g} \mathrm{CuCl}_{2}$, $100 \mathrm{ml} \mathrm{HCl}$ and $100 \mathrm{ml}$ ethanol at $9 \mathrm{~V}$ etching potential for $10 \mathrm{~s}[1,2]$. Fractographs of tensile test failures were observed using a scanning electron microscope (SEM; Hitachi S-4100) operating at $15 \mathrm{kV}$. The thin foils were prepared at the rupture region and observed under transmission electron microscopy (TEM) with an $\mathrm{LaB}_{6}$ filament at an accelerated voltage of $200 \mathrm{kV}$. Samples were sliced and ground down to $0.06 \mathrm{~mm}$ by $\mathrm{SiC}$ abrasion papers, then punched into disks of $3 \mathrm{~mm}$ diameter. Each disk was electropolished to a thin foil in a solution composed of 5 vol.\% perchlorate, 25 vol. $\%$ glycerol and 75 vol.\% ethanol by using a twin-jet at a temperature maintained between -5 and $-10{ }^{\circ} \mathrm{C}$. The electropolishing parameters were a potential of $30 \mathrm{~V}$ and a current of $10 \mathrm{~mA}$.

The flow stress curves of the superaustenitic at different strain rates are shown in Figure 1. It is found that the longer flat-top strain and higher work-hardening rate occur at the higher strain rate (Fig. 1). The summarized ultimate tensile strength (UTS) and the yield strength (YS) are plotted in Figure 2, which shows that these strengths are not strongly influenced by the variation of strain rate. The average YS is about $430 \mathrm{MPa}$, and the average UTS is about $750 \mathrm{MPa}$. On the contrary, the total elongation is conspicuously higher with strain rate increases, as shown in Figure 2. The reduction in area is also reduced with increasing strain rate

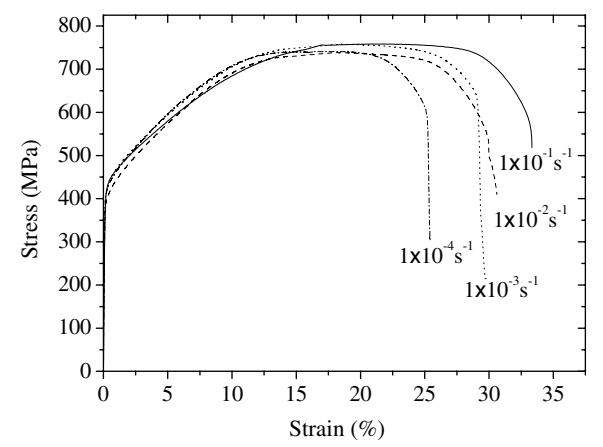

Figure 1. Stress-strain curves of superaustenitic stainless steel at different strain rates.

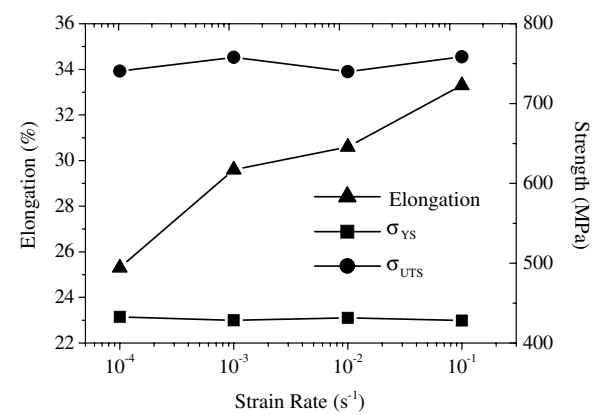

Figure 2. Correlations between the elongation and strength with the strain rate.

in Table 2. This trend of the ductility vs. strain rate violates the normal condition that the elongation reduces as the strain rate increases. For example, the elongation would be $33 \%$ at a strain rate of $1 \times 10^{-1} \mathrm{~s}^{-1}$, but $25 \%$ at a strain rate of $1 \times 10^{-4} \mathrm{~s}^{-1}$. In the meantime, more shear bands formed in the grain at the high strain rate of $1 \times 10^{-1} \mathrm{~s}^{-1}$ than at the low strain rate of $1 \times 10^{-4} \mathrm{~s}^{-1}$, as depicted in Figure 3 . The metallography of superaustenitic 254 SMO steel is the same as the normal austenitic stainless steel, consisting of mono-austenite phase and inlaid twin crystals in some grains. The fracture surfaces of tensile specimens at four different test strain rates were examined by SEM. In the representative fracture there are a large number of ductile dimples with several big "volcanic" craters. The dimples and craters become larger and nonuniform distribution

Table 2. The values of the reduction area $\left(\mathrm{RA}^{\mathrm{O}} \%\right)$ and the strainhardening exponent

\begin{tabular}{lll}
\hline Strain rate $\left(\mathrm{s}^{-1}\right)$ & $\mathrm{RA} \%$ & $n$ \\
\hline $1 \times 10^{-1}$ & 66.8 & 0.29 \\
$1 \times 10^{-2}$ & 58.6 & 0.26 \\
$1 \times 10^{-3}$ & 53 & 0.25 \\
$1 \times 10^{-4}$ & 52.3 & 0.24 \\
\hline
\end{tabular}

Table 1. Chemical composition of the 254 SMO stainless steel (GDS) (wt.\%)

\begin{tabular}{llllllllllllll}
\hline 254SMO & $\mathrm{Ni}$ & $\mathrm{Cr}$ & $\mathrm{Mo}$ & $\mathrm{C}$ & $\mathrm{Si}$ & $\mathrm{Mn}$ & $\mathrm{P}$ & $\mathrm{S}$ & $\mathrm{N}$ & $\mathrm{Cu}$ & $\mathrm{Co}$ & $\mathrm{V}$ \\
\hline Avesta spec. & 17.86 & 20.01 & 6.18 & 0.012 & 0.31 & 0.47 & 0.023 & 0.001 & 0.208 & 0.72 & - & - \\
Analysis & 17.77 & 19.46 & 5.78 & 0.011 & 0.31 & 0.46 & 0.019 & 0.003 & 0.16 & 0.67 & 0.18 & 0.08 \\
\hline
\end{tabular}




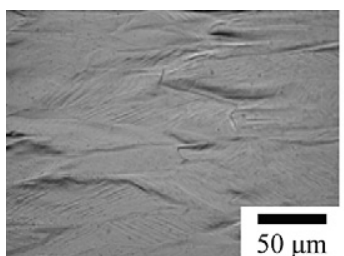

(a) strain rate $1 \times 10^{-1} \mathrm{~s}^{-1}$

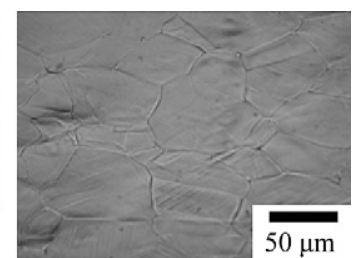

(b) strain rate $1 \times 10^{-4} \mathrm{~s}^{-1}$
Figure 3. Optical micrograph of the deformed superaustenitic stainless steel at two representative strain rates.

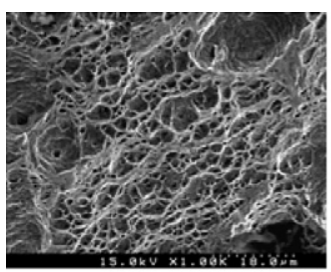

(a) strain rate $1 \times 10^{-1} \mathrm{~s}^{-1}$

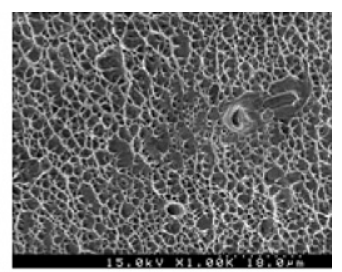

(b) strain rate $1 \times 10^{-4} \mathrm{~s}^{-1}$
Figure 4. The fracture surface of superaustenitic stainless steel after tensile failure.

increases with increasing strain rate, as shown in Figure 4. The high-resolution microstructures after deformation at the failure region were analyzed to investigate the relation between the mechanical properties and the deformation mechanism. The representative high-resolution microstructures in Figure 5 show the specimens subjected to the deformation at strain rates of $1 \times 10^{-4}$ and $1 \times 10^{-1} \mathrm{~s}^{-1}$, in addition to that of the as-received metal. The microstructure of the as-received superaustenitic stainless steel reveals tangled dislocations along the primary slip traces, as shown in Figure 5a.

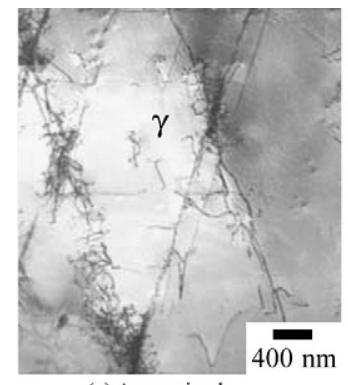

(a) As-received

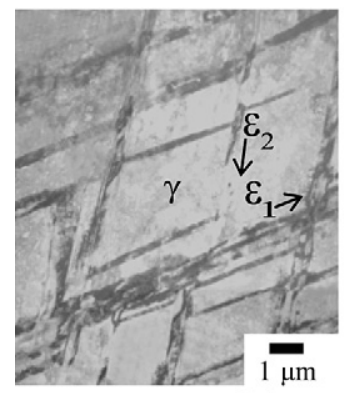

(c) strain rate $1 \times 10^{-1} \mathrm{~s}^{-1}$

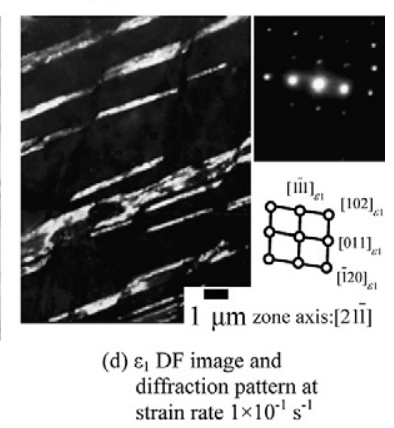

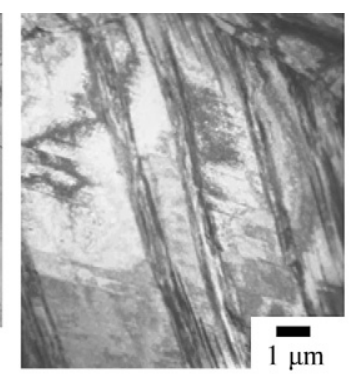

(b) strain rate $1 \times 10^{-4} \mathrm{~s}^{-1}$

Figure 5. Microstructure of superaustenitic stainless steel at (a) asreceived and deformed samples at strains, (b) $1 \times 10^{-4} \mathrm{~s}^{-1}$, (c) $1 \times$ $10^{-1} \mathrm{~s}^{-1}$ and (d) dark field (DF) and diffraction pattern at $1 \times 10^{-1} \mathrm{~s}^{-1}$.
In contrast, the microstructures of the deformed specimen exhibit one oriented band at the lowest strain rate of $1 \times 10^{-4} \mathrm{~s}^{-1}$ (Fig. 5b) and two intersected bands at the highest strain rate of $1 \times 10^{-1} \mathrm{~s}^{-1}$ (Fig. 5c). The bands in the $\gamma$ phase of the austenitic matrix have been identified as the hexagonal $\varepsilon$ phase matrix, as shown in Figure $5 \mathrm{~d}$. It has been proposed that in the straining process, the atomic arrangement is shifted from the face-centered cubic (fcc) $\gamma$ phase to the hexagonal $\varepsilon$ phase of martensite plate. The strain-induced martensite could hinder the moving dislocation, increase the workhardening rate, delay the occurrence of rupture and extend the elongation of the material. Comparison of the amount of strain-induced $\varepsilon$ martensite in Figure 5 shows that the number of $\varepsilon$ martensite plates increases with strain rate qualitatively under the same magnification. The number and the size of craters as well as the size of dimples increase as strain rate increases (Fig. 4), which could be due to the increasing number of induced $\varepsilon$ martensite intersections.

At the slowest strain rate of $1 \times 10^{-4} \mathrm{~s}^{-1}$, few dislocation and slip traces can be found (Fig. 5b), indicating that the materials can accommodate deformation through formation of $\varepsilon$ martensite. These $\varepsilon$ martensite plates, containing stacking faults, belong to one variant which is favorable to the tensile deformation. With further high strain rate deformation, dislocations and more $\varepsilon$ martensite plates appear. At the highest strain rate of $1 \times 10^{-1} \mathrm{~s}^{-1}$, slip deformation by dislocations and the formation of intersected martensite with another variant occurs, as shown in Figure 5c.

High plastic strain exerted a large amount of strain energy on the material, and the energy was dissipated via crystal defect formation, leading to the phase transformation and an increase in temperature. The measured surface temperature of the specimen was about $80^{\circ} \mathrm{C}$ at the highest strain rate of $1 \times 10^{-1} \mathrm{~s}^{-1}$ during the uniaxial tensile test. The magnitude of the temperature rise can be calculated with an integral equation [12]:

$\Delta T=\left(\frac{1}{\rho C_{p}}\right) \int_{0}^{\varepsilon} \sigma \mathrm{d} \varepsilon$,

where $\Delta T$ is the temperature rise, $\rho$ is the density $\left(8 \mathrm{~g} \mathrm{~cm}^{-3}\right), C_{p}$ is the heat capacity $\left(0.1195 \mathrm{cal} \mathrm{g}^{-1}\right.$ per $\left.{ }^{\circ} \mathrm{C}\right), \sigma$ is the stress and $\mathrm{d} \varepsilon$ is the interval of strain. This calculation has been made for each stress-strain curve of the tested strain rate conditions in Figure 1. The calculated temperatures are $79,74,71$ and $65^{\circ} \mathrm{C}$ at the strain rates of $1 \times 10^{-1}, 1 \times 10^{-2}, 1 \times 10^{-3}$ and $1 \times 10^{-4} \mathrm{~s}^{-1}$, respectively. The temperature rises more as the strain rate increases because there is less time for the heat to dissipate to the environment. The calculated result of $79^{\circ} \mathrm{C}$ at the highest strain rate of $1 \times 10^{-1} \mathrm{~s}^{-1}$ is in good agreement with the measured value of $80^{\circ} \mathrm{C}$. The heat generated by the high strain rate of $1 \times 10^{-1} \mathrm{~s}^{-1}$ assists in the dislocation motion, cross slip and interaction. These changes result in good ductility and long elongation. This high elongation of tensile deformation facilitates an increase in operative microscopic shear band (deformation twins, stacking fault bundles and $\varepsilon$-martensite) intersection. The intersection is regarded as an effective site for strain-induced 


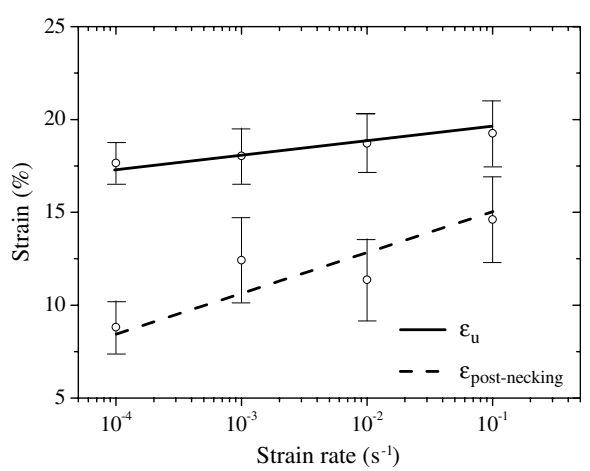

Figure 6. The trend of uniform strain $\varepsilon_{\mathrm{u}}$ and post necking elongation $\varepsilon_{\mathrm{pn}}$ versus strain rate.

martensite nucleation [13]. Therefore, the above changes induce martensite nucleation and growth and prompt the austenite to transform into martensite. As a consequence of this martensite formation, the value of the strain-hardening exponent $(n)$ increases with strain rate, as seen in Table 2. A high value of $n$, representing a strong ability of the material to retard necking, delays necking to rupture, and then results in a large value of post-necking elongation. It is suggested that the higher temperature generated from the high strain rate will cause more strain-induced $\varepsilon$ martensite formation, which is beneficial to the ductility [11]. Thus, if $\varepsilon$ martensite is produced uniformly in the straining, this superaustenitic steel should have longer elongation $[9,10,14]$.

Looking at it another way, the uniform elongation $\varepsilon_{\mathrm{u}}$ slightly increases with the strain rate, but the post-necking elongation $\varepsilon_{\mathrm{pn}}$ increases significantly, as depicted in Figure 6 . The higher elongation at the high strain rate could be explained by the fact that in these materials necking is delayed, and they rather rupture naturally as the strain-hardening increases, resulting in an increase in elongation $[5,6,15]$. Under strain, ductile $\varepsilon$ martensite induced by phase transformation could accommodate or hinder the moving dislocation and increase strainhardening to delay the necking.

It is proposed that the high $\mathrm{Ni}$ and Mo alloying content of this superaustenitic stainless steel may reduce the stacking fault energy (SFE) in the $\gamma$ phase. The SFE with the alloying addition plays an important role in the determination of the critical driving force, $\triangle G_{\mathrm{c}} \gamma \rightarrow \varepsilon$, and martensitic transformation start temperature, $M_{\mathrm{S}}$ [16]. In the alloys with low SFE, such as $\mathrm{Fe}-\mathrm{Mn}-\mathrm{Si}$ [17], $\mathrm{Co}-\mathrm{Ni}$ and $\mathrm{Co}-\mathrm{Cu}$ [18], the nucleation of $\varepsilon$ martensite may occur directly through stacking faults [18]. The martensite transformation from the fcc austenite $\gamma$ phase to the hexagonal close packed (hcp) $\varepsilon$ martensite plate can be accomplished by introducing stacking faults on a $\{111\}$ plane every two layers [19]. There are three possible displacement vectors of this faulting on a given \{111\} plane, $1 / 6[\overline{1} \overline{1} 2], 1 / 6[\overline{1} 2 \overline{1}]$ or $1 / 6[2 \overline{1} \overline{1}]$ on a (111) plane, to produce an hep $\varepsilon$ martensitic plate [19]. As the strain rate of deformation increases, the higher temperature of the specimen, which is favorable to the atomic movement, is generated by adiabatic dissipation of the stored strain energy. Therefore, the volume frac- tion of strain-induced $\varepsilon$ martensite increases, which should raise the magnitude of the post-necking elongation contribution in Figure 5, which in turn gives rise to higher ductility. The trend of increases in post-necking elongation with increasing strain rate almost linearly, shown in Figure 6, is very similar and comparable to the increases in the volume fraction of $\varepsilon$ martensite linearly with increasing degrees of cold rolling up to $3 \%$ [20].

The strain rate does not affect the yield strength or tensile strength of superaustenitic stainless steel, but it is beneficial to the ductility, i.e., longer elongation results from higher strain rates. The number and the size of craters, as well as the size of dimples, increase with strain rate, which could be associated with the increase of intersections of $\varepsilon$ martensite plates. Under high strain rate, the increasing temperature is favorable to the induced $\varepsilon$ martensite formation at two different orientations. Large quantities of strain-induced martensite and the intersections can facilitate the strain-hardening effect and delay the onset of necking. Finally, the ductility of the superaustenitic steel can be improved by high strain rate deformation.

This work was carried out with financial support from the National Science Council of the Republic of China, Taiwan, grant NSC-93-2216-E-019-003. The authors gratefully acknowledge this support.

[1] M.A. Anjos, R. Vilar, Y.Y. Qiu, Surf. Coat. Technol. 92 (1997) 142.

[2] C.S. Huang, S.H. Wang, C.C. Wu, Y.S. Huang, Jason Fang, Scripta Metall. 54 (2006) 1181.

[3] C.S. Huang, S.H. Wang, W.S. Lee, T.H. Chen, C. Lien, Scripta Metall. 52 (2005) 843.

[4] Alfred Goldberg, Kenneth G. Hoge, Mater. Sci. Eng. 13 (1974) 211.

[5] M. Bostshekan, S. Degallaix, Y. Desplanques, J. Polak, Fatigue Fract. Eng. Mater Struct. 21 (1998) 651.

[6] M. Bostshekan, S. Degallaix, Y. Desplanques, Mater. Sci. Eng. A. 234-236 (1997) 463.

[7] E. Nagy, V. Mertinger, F. Tranta, J. Sólyom, Mater. Sci. Eng. A. 378 (2004) 308.

[8] H.Y. Yu, S.H. Li, Y.K. Gao, Mater. Char. (2006).

[9] K. Spencer, J.D. Embury, K.T. Conlon, M. Vron, Y. Brchet, Mater. Sci. Eng. A. 387-389 (2004) 8731.

[10] P.K. Chiu, K.L. Weng, S.H. Wang, J.R. Yang, J. Fang, Mater. Sci. Eng. A. 398 (2005) 349.

[11] P.K. Chiu, S.H. Wang, J.R. Yang, K.L. Weng, J. Fang, Mater. Chem. Phys. 98/1 (2006) 103.

[12] W.S. Lee, G.L. Xiea, C.F. Lin, Mater. Sci. Eng. A. 257 (2001) 256.

[13] L.E. Murr, K.P. Staudhammer, S.S. Hecker, Metall. Trans. A 13 (1982) 627.

[14] P.L. Mangonon Jr., G. Thomas, Metall. Trans. 1 (1970) 1577.

[15] N. Hashimoto, S.J. Zinkle, A.F. Rowcliffe, J.P. Robertson, S. Jitsukawa, J. Nucl. Mater. 283-287 (2000) 528.

[16] T.Y. Hsu, Xu Zuyao, Mater. Sci. Eng. A 273-275 (1999) $494-497$.

[17] J. Li, C.M. Wayman, Scripta Metall. Mater. 27 (1992) 279.

[18] T.Y. Hsu, Acta Metall. Sin. 16 (1980) 430.

[19] S. Kajiwara, Mater. Sci. Eng. A. 273-275 (1999) 67.

[20] K.K. Jee, S.H. Baik, B.J. Lee, M.C. Shin, C.S. Choi, Scripta Metall. et Materialia 33 (1995) 1901-1905. 